
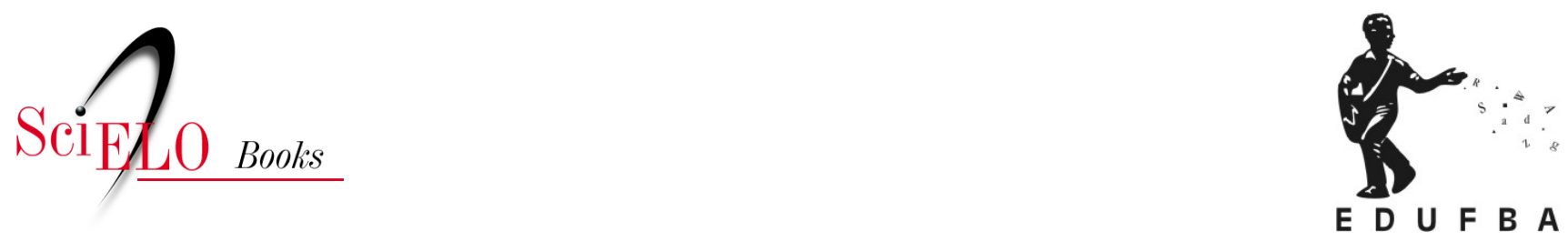

\title{
Reflexões \\ Liberdade para a internet (e para tudo!)
}

\author{
Nelson De Luca Pretto
}

PRETTO, N.D.L. Liberdade para a internet (e para tudo!). In: Educações, culturas e hackers: escritos e reflexões [online]. Salvador: EDUFBA, 2017, pp. 114-117. ISBN: 978-85-232-2019-8.

https://doi.org/10.7476/9788523220198.0018.

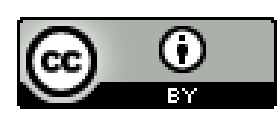

All the contents of this work, except where otherwise noted, is licensed under a Creative Commons Attribution $\underline{4.0 \text { International license. }}$

Todo o conteúdo deste trabalho, exceto quando houver ressalva, é publicado sob a licença Creative Commons Atribição 4.0. 
No caso brasileiro, representa mais uma chance para intensificarmos a pressão sobre os nossos deputados federais para que não continuem, no afogadilho, aprovando leis isoladas que tipificam crimes na internet, sem antes aprovar o seu Marco Civil, garantia dos direitos do cidadão na web. Quando pautada, a votação tem sido sistematicamente adiada em função de um poderoso lobby contrário à internet livre e em defesa dos interesses das grandes corporações.

Em 2008, Arron Swartz lançou o Manifesto Guerrilha, um testamento em defesa da livre circulação da informação científica, exaustivamente citado nos últimos dias. Para ele, "se somarmos muitos de nós, não vamos apenas enviar uma forte mensagem de oposição à privatização do conhecimento - vamos transformar essa privatização em algo do passado."

O Manifesto termina com a conclamação: "Você vai se juntar a nós?". Vamos, diremos em alto e bom som!

Publicado no jornal Correio ${ }^{*}$, Salvador, em 28 de janeiro de 2013.

\section{Liberdade para a internet (e para tudo!)}

No mês passado (junho de 2015), escrevi sobre os movimentos abertos, com destaque para a Ciência Aberta. Foi uma primeira provocação para abrir o mês de julho, pois já sabia que, ao longo do mês, teríamos um conjunto de atividades que retomariam o tema, direta ou indiretamente. Aqui da Bahia, comemoramos o Dois de Julho, data da sua Independência (e do Brasil), dia comemorado pelos baianos com muita festa, euforia, participação popular e, claro, com muita reivindicação política. Nessa data, em 1823, os baianos expulsaram os portugueses, declarando a independência da Bahia, com isso consolidando a independência do Brasil. O Dois de 
Julho passou a ser data cívica nacional a partir de 2013 com o projeto de lei 6.576/2006 da deputada baiana Alice Portugal. ${ }^{10}$ Um projeto muito bacana realizado pelo Instituto do Patrimônio Artístico e Cultural (IPAC), do governo da Bahia, em parceria com a turma da Oi Kabum e a Galeria 2 de Julho, onde encontramos fotos das celebrações da data, produzidas por jovens fotógrafos. ${ }^{11}$ A orquestra Neojibá com o cantor Tatau gravaram o hino que celebra a data. ${ }^{12}$

Depois do Dois de Julho, tivemos o $16^{\circ}$ Fórum Internacional do Software Livre (FISL 16) ${ }^{13}$, ocorrido na PUC do Rio Grande do Sul, em Porto Alegre e, depois, a $67^{\text {a }}$ Reunião Anual da Sociedade Brasileira para o Progresso da Ciência (SBPC), em São Carlos, no interior de São Paulo. Em ambas, estiveram presentes, de forma muito intensa, o tema da ciência aberta, das políticas de informação científica, a governança da internet, especialmente com os debates sobre o Marco Civil.

Para fechar o mês, completando a rodada que engrandeceu o nosso julho de 2015, tivemos o V Fórum da Internet no Brasil, ${ }^{14}$ organizado pelo Comitê Gestor da Internet (CGI). O Fórum é uma iniciativa do CGI, desde 2011, e já foi realizado em diversas cidades do país. Destaco a fundamental politica de financiamento para que representes da sociedade civil e da academia possam efetivamente participar dos debates. Essa é uma acertada politica que garante a igualdade de participação em relação àqueles que têm condições financeiras para se deslocar até o Fórum e, com isso, influenciar nas decisões coletivas tomadas nos encontros.

Em todos os três eventos que mencionei, nos quais estive presente, insisti na necessidade de uma forte articulação das políticas públicas, superando assim aquilo que venho denominando de políticas públicas esquizofrênicas, ou seja, cada ministério ou secretaria estadual desenvolve sua política e uma não fala com as demais.

\footnotetext{
${ }^{10}<$ http://www.camara.gov.br/proposicoesWeb/fichadetramitacao?idProposicao=313014>.

${ }^{11}<$ http://galeriadoisdejulho.blogspot.com.br>.

${ }_{12}<$ Para ouvi-lo: https://www.youtube.com/watch?v=vbd6Qre35hQ>.

${ }^{13}<$ http://softwarelivre.org/fisl16>.

${ }^{14}<$ http://forumdainternet.cgi.br $>$.
} 
No caso no Fórum da Internet, insisti que "para conectar o próximo bilhão na internet, necessitamos de políticas públicas conectadas!”. Isso porque, em última instância, o que queremos é uma internet que favoreça a participação cidadã de todos e, para tal, precisamos de uma banda larga que seja de fato larga, ou seja, não podemos nos satisfazer com qualquer conexão. Precisamos de uma banda larga que possibilite toda a sociedade e não apenas aqueles que podem pagar privadamente por isso, usufruir plenamente a rede, utilizando-a com todos os suportes (texto, áudio, vídeo, simulações etc). A Federal Communication Comision (FCC) americana, em 2013, passou a definir banda larga como sendo aquelas conexões de mais de $25 \mathrm{Mbps}$, subindo dos antigos $4 \mathrm{Mbps}$, que era a velocidade mínima para uma conexão ser considerada larga. ${ }^{15}$ Claro que esse patamar mínimo é variável no tempo, uma vez que aumentam as possibilidades de atividades via rede e, cada vez mais, com a chamada internet das coisas, isso será ampliado e precisa ser acompanhado pelas políticas públicas.

Sabemos que não conseguiremos, num prazo curto, dotar todas as residências, independentemente de classe social, com conexões com esse patamar de velocidade, por isso insistimos na importância de se pensar nos espaços públicos como privilegiados para a chamada inclusão social e digital. Aqui, destaque há de ser feito para as escolas e os espaços comunitários (Pontos de Cultura, Associações comunitárias, praças, entre outros).

Para que isso aconteça, não podemos nos contentar com uma internet onde sejamos dominados pelos app que nos permitem apenas fazer o que lá está programado. Mais do que tudo, não podemos aceitar que as políticas chamadas de inclusão digital sejam realizadas a partir de uma camada privada de infraestrutura ou plataformas, a exemplo de projetos como os que agora vemos ser anunciados (sem, no entanto, muita precisão sobre o que está sendo negociado) pelo governo brasileiro e o Facebook para viabilizar a chamada inclusão digital.

A construção dessas políticas públicas demanda uma ampla participação da sociedade nas suas definições e isso tem que ser feito desde o

\footnotetext{
${ }^{15}<$ http://www.theverge.com/2015/1/29/7932653/fcc-changed-definition-broadband$25 \mathrm{mbps}>$.
} 
começo! Por isso o tema da liberdade e, aí, consideramos fundamental contemplar, de forma explícita e indutiva, o fortalecimento do software livre e, mais ainda, de políticas industriais, científicas e tecnológicas que favoreçam o desenvolvimento, a criação e a disseminação de hardwares livres.

Foram muitas as manifestações ocorridas durante as falas no Fórum da Internet no Brasil e todo esse material já está disponível no site do Comitê Gestor da Internet. Destaco aqui a carta aprovada e assinada por diversas entidades presentes ou não do Fórum em Salvador, onde os signatários afirmaram, com todas as letras, ser "necessário impedir que novas iniciativas de regular o uso da rede deturpem os princípios e garantias já estabelecidos, os quais foram amplamente discutidos com toda a sociedade". Termina a carta defendendo "a internet livre como uma rede preciosa à criação colaborativa, à liberdade de expressão, à mobilização social e ao fortalecimento de diversos direitos fundamentais, como a comunicação, a cultura e o acesso à informação, com atenção à pluralidade e à diversidade para empoderar mulheres, jovens, e o midialivrismo étnico-racial nacional e internacional". ${ }^{16}$

"Nunca mais o despotismo, regerá nossa nação. Com tiranos não combinam, brasileiros corações”, diz o hino ao Dois de Julho. Trazemos para cá o nosso hino. Não queremos nossa internet como sendo mais uma forma de colonização. Liberdade para a nossa internet!

Publicado no portal A Rede17, São Paulo, em 14 de julho de 2015.

\footnotetext{
${ }^{16}$ Veja na íntegra: <http://forumdainternet.cgi.br/library/CartaSalvador.html>.

${ }^{17}$ Disponível em: <http://www.arede.inf.br/author/nelsonpretto $>$.
} 